\title{
A 52-Week Study of Olanzapine with a Randomized Behavioral Weight Counseling Intervention in Adolescents with Schizophrenia or Bipolar I Disorder
}

\author{
Holland C. Detke, PhD, ${ }^{1}$ Melissa P. DelBello, MD, ${ }^{2}$ John Landry, MMath, \\ Vicki Poole Hoffmann, PharmD, ${ }^{1}$ Alexandra Heinloth, MD, and Ralf W. Dittmann, MD, PhD 5
}

\begin{abstract}
Objectives: To evaluate the 52-week safety/tolerability of oral olanzapine for adolescents with schizophrenia or bipolar mania and compare effectiveness of a standard versus intense behavioral weight intervention in mitigating risk of weight gain.

Methods: Patients 13-17 years old with schizophrenia (Brief Psychiatric Rating Scale for Children [BPRS-C] total score >30; item score $\geq 3$ for hallucinations, delusions, or peculiar fantasies) or bipolar I disorder (manic or mixed episode; Young Mania Rating Scale [YMRS] total score $\geq 15)$ received open-label olanzapine $(2.5-20 \mathrm{mg} / \mathrm{day})$ and were randomized to standard ( $n=102$; a single weight counseling session) or intense ( $n=101$; weight counseling at each study visit) weight intervention. The primary outcome measure was mean change in body mass index (BMI) from baseline to 52 weeks using mixed-model repeated measures. Symptomatology was also assessed.

Results: No statistically significant differences between groups were observed in mean baseline-to-52-week change in BMI (standard: $+3.6 \mathrm{~kg} / \mathrm{m}^{2}$; intense: $+2.8 \mathrm{~kg} / \mathrm{m}^{2} ; p=0.150$ ) or weight (standard: $+12.1 \mathrm{~kg}$; intense: $+9.6 \mathrm{~kg} ; p=0.148$ ). Percentage of patients at endpoint who had gained $\geq 15 \%$ of their baseline weight was $40 \%$ for the standard group and $31 \%$ for the intense group $(p=0.187)$. Safety/tolerability results were generally consistent with those of previous olanzapine studies in adolescents, with the most notable exception being the finding of a mean decrease in prolactin. On symptomatology measures, patients with schizophrenia had a mean baseline-to-52-week change in BPRS-C of -32.5 (standard deviation [SD] $=10.8$ ), and patients with bipolar disorder had a mean change in YMRS of -16.7 (SD = 8.9), with clinically and statistically significant improvement starting at 3-4 days for each.

Conclusions: Long-term weight gain was high in both groups, with no statistically significant differences between the standard or intense behavioral weight interventions in BMI or weight. Safety, tolerability, and effectiveness findings were generally consistent with the known profile of olanzapine in adolescents.
\end{abstract}

Keywords: olanzapine, adolescent, weight management, schizophrenia, bipolar, counseling

\section{Introduction}

Chizophrenia AND Bipolar Disorder are serious and generally lifelong disorders that often begin during adolescence (American Psychiatric Association 2000). It is estimated that $39 \%$ of men with schizophrenia and $23 \%$ of women with schizophrenia experience onset of the illness before age 19 years (Loranger 1984); peak age of onset of first symptoms of bipolar disorder is reported to occur between age 15 and 19 years (Bauer and Pfennig 2005). Childhood onset (by age 12 years) of these disorders is less common but is often associated with greater severity of illness (McClellan et al. 1993; Strober et al. 1995; Wozniak et al. 1995; Hollis 2000; Kumra et al. 2001; Remschmidt and Theisen 2012). In both disorders, early and effective treatments may improve the long-term outcomes (Tohen 1997; Hollis 2000; Post et al. 2010).

Second-generation antipsychotics are effective and commonly used to treat schizophrenia and bipolar mania in adults and adolescents. Weight gain and other adverse metabolic changes often accompany treatment with second-generation antipsychotics (Moreno et al. 2010; Correll et al. 2011; Datta et al. 2014). Such metabolic

\footnotetext{
${ }^{1}$ Lilly Research Laboratories, Indianapolis, Indiana.

${ }^{2}$ Department of Psychiatry, University of Cincinnati College of Medicine, Cincinnati, Ohio.

${ }^{3}$ Eli Lilly Canada, Danforth, Ontario, Canada.

${ }^{4}$ inVentiv Health Clinical, LLC, Ann Arbor, Michigan.

${ }^{5}$ Paediatric Psychopharmacology, Department of Child and Adolescent Psychiatry and Psychotherapy, Central Institute of Mental Health, Medical Faculty Mannheim, University of Heidelberg, Mannheim, Germany.

Previously submitted at 27th Congress of the European College of Neuropsychopharmacology, October 18-21, 2014, Berlin, Germany; 61st Annual Meeting of the American Academy of Child \& Adolescent Psychiatry, October 20-26, 2014, San Diego, CA.

Funding: This study was sponsored by Eli Lilly and Company.
} 
changes not only may be of concern due to the potential long-term health risk to the patient but also can be a significant potential obstacle to patients (or their parents) agreeing to start such a treatment or practice medication adherence (Weiden et al. 2004). Compounding the treatment-emergent weight gain in adolescents with bipolar disorder are poorer nutritional behaviors due to stress-induced eating (Martin et al. 2016) and lower levels of physical activity (Jewell et al. 2015) in this patient population compared with control groups.

Strategies recommended for preventing or ameliorating weight gain in children and adolescents treated with second-generation antipsychotics include controlling the environment, monitoring behavior, setting goals, rewarding successful behaviors, identifying and solving problems, and adapting parental skills (Correll and Carlson 2006). Goldstein et al. (2011) developed a brief motivational intervention for preventing treatment-emergent weight gain among youth with bipolar disorder.

Olanzapine is a second-generation antipsychotic that has demonstrated efficacy in adolescents with schizophrenia (Kryzhanovskaya et al. 2009a) and adolescents with manic or mixed episodes of bipolar disorder (Tohen et al. 2007). Results from these studies also indicated clinically significant weight gain and metabolic changes after 3 weeks (Tohen et al. 2007) and 6 weeks (Kryzhanovskaya et al. 2009a) of randomized, double-blind treatment with olanzapine relative to placebo, with continued changes up to 26 additional weeks of open-label treatment (McCormack 2010). Pooled safety results from the adolescent olanzapine trials (Kryzhanovskaya et al. 2009b) indicated similar types of adverse events as seen in adults treated with olanzapine. In contrast to previous observations in adults, adolescent patients were found to have a greater magnitude and incidence of weight gain, as well as greater changes in lipids (specifically total cholesterol, low-density lipoprotein cholesterol, and triglycerides), hepatic enzymes, prolactin, and sedation (Kryzhanovskaya et al. 2012; Eli Lilly and Company 2013).

These findings may be of concern for many clinicians when evaluating how best to manage serious mental illness in this vulnerable adolescent population. Clinicians should consider the potential long-term risks when treating adolescents with olanzapine and whether some of these risks can be proactively mitigated. Current guidance on treating with a second-generation antipsychotic includes educating patients on a healthy lifestyle and the need to reduce caloric intake and to increase exercise (Citrome et al. 2005; Tschoner et al. 2007). Some evidence supports the effectiveness of these methods in adults (Faulkner et al. 2007; Pendlebury et al. 2007; Alvarez-Jimenez et al. 2008; Holt et al. 2010), but few studies have evaluated such methods specifically in adolescents treated with second-generation antipsychotics.

The current study was conducted at the request of the U.S. Food and Drug Administration as a condition of approval of olanzapine for use in adolescents with schizophrenia or bipolar I disorder (manic or mixed episodes). The primary objective of the study was twofold: (1) to evaluate the longer term safety and tolerability of olanzapine in this population and (2) to evaluate whether an intense behavioral weight intervention would be superior to a standard behavioral weight intervention in the mitigation of weight gain in adolescent patients treated with olanzapine as measured by overall mean change from baseline in body mass index (BMI).

\section{Methods}

\section{Patient selection}

Patients were inpatients or outpatients, aged 13-17 years, and diagnosed with schizophrenia or bipolar I disorder (manic or mixed episode) according to the Diagnostic and Statistical Manual of Mental Disorders, Fourth Edition, Text Revision (DSM-IV-TR) (American Psychiatric Association 2000) and as confirmed by the Kiddie Schedule for Affective Disorders and Schizophrenia for School Aged Children-Present and Lifetime (K-SADS-PL) (Kaufman et al. 1997). Patients with schizophrenia had a Brief Psychiatric Rating Scale for Children (BPRS-C) (Overall and Pfefferbaum 1982) total score of $>30$, with an item score $\geq 3$ for hallucinations, delusions, or peculiar fantasies at screening and randomization. Patients with bipolar I disorder had a Young Mania Rating Scale (YMRS) (Young et al. 1978) total score of $\geq 15$ at screening and randomization.

Patients were excluded if they had an acute, serious, or unstable medical condition; a history of mental retardation; a current diagnosis of autism or pervasive developmental disorder; a diagnosis of substance dependence other than nicotine or caffeine within 30 days before study entry; or were judged to be at risk for suicide. Patients were also excluded if they were receiving pharmaceutical treatment for weight management or were participating in a structured behavioral diet and/or exercise weight loss program. Patients should not have received olanzapine for $\geq 5$ days during the month before screening and could not have a history of allergic reaction or inability to tolerate or respond to olanzapine.

\section{Study design}

This was a phase 4, single-drug arm, open-label, safety and tolerability study of oral olanzapine with a randomized, unblinded behavioral weight intervention conducted between September 2009 and May 2013 at 29 centers in the United States, Russia, Poland, and Germany. Before patient enrollment, the appropriate institutional review boards evaluated and approved the study protocol. Written informed assent and consent were obtained from each patient and his or her legal guardian, respectively, at study entry and before commencement of any study procedures. The study was conducted in full accordance with ethical principles of Good Clinical Practice (GCP) (Fromell 2008) and the Declaration of Helsinki and its guidelines (Parsa-Parsi et al. 2014).

On enrollment, patients entered a 2- to 14-day screening and washout period during which all antipsychotic, anticonvulsant, and mood stabilizing medications had to be discontinued at least 2 days before entry into the open-label treatment period. Eligible patients then entered a 52-week open-label treatment period and were initiated on oral olanzapine at a starting dose of 2.5 or $5 \mathrm{mg} /$ day based on initial patient assessment and at the discretion of the investigator. Dosing thereafter was flexible within a range of $2.5-20 \mathrm{mg} /$ day, with dose changes allowed in 2.5 or $5 \mathrm{mg}$ increments as needed. No adjunctive antipsychotics, mood stabilizers, anticonvulsants, or medications prescribed specifically for weight management were allowed during the study. Psychostimulants or medications with potential weight-altering effects were allowed only if the patient had been on a stable dose for at least 2 weeks before study enrollment and if prescribed for use other than for weight management.

Patients were seen twice in week 1 , then weekly through week 4 , every 2 weeks through week 8 , and then every 4 weeks through week 52. Effectiveness, safety, and tolerability were assessed at each visit.

On entry into the open-label olanzapine treatment period, patients were randomized in a 1:1 ratio into two weight intervention groups, a standard behavioral weight counseling intervention (standard group) or an intense behavioral weight counseling intervention (intense group). The standard intervention consisted of a single counseling session only at time of randomization for both the 
patient and the patient's parent/guardian. This session was at least 15 minutes in duration (with no maximum time limit), during which time the participants received basic information on healthy eating and exercise habits. The intense intervention consisted of counseling sessions of at least 15-minute duration at every study visit for both the patient and the parent/guardian.

Counseling sessions were led by clinical site personnel who had been trained on the intervention program, and it was recommended that sites use the same counselor for the patient from visit to visit. Each counseling session included discussion of prespecified information and handouts on healthy eating (food selection) and/or healthy exercise (physical activity) habits, with different topics and guidance covered at each visit, adapted from the Smart Moves ${ }^{\mathrm{TM}}$ weight management program (Savoye et al. 2007).

Both participants and parents/guardians in the intense group were introduced to "lifestyle logs" (food and exercise logs for recording daily physical activity and food/beverage intake) and received training on the importance of healthy food choices, portion control, a balanced diet, and regular exercise, as well as education about nutrition, calories, and metabolism. Participants in the intense intervention also received a pedometer to encourage exercise and tracking of exercise. Each session included review of patient eating and exercise habits since the last visit and potential introduction of behavior modification strategies (such as goal setting and strategies for overcoming barriers to success). Counselors were asked to focus on and help participants identify positive behaviors in the lifestyle logs to encourage further positive behaviors. Counseling sessions thus included a combination of education, problem solving, and motivational enhancement in a family counseling setting.

Patients in the intense group who met criteria for obesity or had a significant weight increase (defined as $B M I \geq 97$ th percentile at baseline or at two or more successive visits or a BMI increase of $\geq 0.5 \mathrm{U}$ at two or more successive visits) received additional tools and guidance to encourage weight reduction, including a bathroom scale for self-monitoring of weight at home and instruction on logging caloric intake and strategies to reduce caloric intake. Participant food and exercise logs were expanded to track feelings and environmental situations tied to eating. Sessions then focused on identifying behavioral patterns and triggers for overeating and developing solutions to avoid and manage such triggers. Participants' lifestyle log entries were not collected or analyzed as part of the study but were used solely as a counseling tool.

\section{Measures}

The primary measure of effectiveness of the behavioral weight interventions was mean change in BMI. Weight and waist circumference were also assessed. In addition to the weight-related assessments, the overall safety and tolerability of oral olanzapine were evaluated through the collection of vital signs, adverse events, laboratory analytes, electrocardiogram (ECG) recordings; the assessment of extrapyramidal symptoms (EPS) using the Abnormal Involuntary Movement Scale (AIMS) (Guy 1976), the Barnes Akathisia Global Score (Barnes 1989), and the Simpson-Angus Total Score (SAS) (Simpson and Angus 1970); and the assessment of suicidality using the Columbia Suicide Severity Rating Scale (C-SSRS) (Posner 2007; Posner et al. 2011). The effectiveness of olanzapine in the treatment of schizophrenia or bipolar mania was assessed using the BPRS-C (Lachar et al. 2001) or YMRS (Young et al. 1978), respectively. All patients' symptom severity was assessed using the Clinical Global Impression-Severity (CGI-S) scale (Guy 1976).
Patient BMI was also analyzed categorically based on the World Health Organization (World Health Organization 2007) pediatric BMI growth charts (2007) by age and gender, with shifts in BMI categories analyzed using percentile cutoffs for underweight $(<5$ th percentile), healthy weight ( $\geq 5$ th to $<85$ th percentile), overweight ( $\geq 85$ th to $<95$ th percentile), and obese ( $\geq 95$ th percentile).

\section{Statistical analyses}

Analyses were conducted on all randomized patients who received at least 1 dose of study medication. Mean changes for BMI (primary endpoint) were assessed using a mixed model repeated measures (MMRM) analysis, which included the model terms of intervention group, region, visit, intervention group-by-visit interaction, baseline BMI, baseline age, and gender. Mean changes in other continuous variables were assessed using MMRM analyses, as well as last observation carried forward (LOCF) analyses, with LOCF intervention group comparisons based on analysis of covariance models; all models varied but included terms for intervention group and baseline.

For comparison of categorical variables, a Fisher's exact test was used. Subgroup analyses were conducted for selected categorical and continuous safety measures, including mean change from baseline in BMI and weight and incidence of specific treatment-emergent adverse events of interest (e.g., "weight increased"). Subgroups included gender (male or female), disease state (schizophrenia or bipolar disorder), race (white or non-white), and geographic region (US or non-US). Continuous outcomes were assessed using an MMRM model similar to that used for the primary outcome analysis, including the terms for baseline, intervention groups, region (if region was not a subgroup variable), subgroup, visit-by-intervention interaction, and the intervention-by-subgroup interaction. The MantelHaenszel common-odds ratio and the Breslow-Day test for homogeneity of odds ratio were used to evaluate differences across the subsets for dichotomous categorical outcomes.

All tests of hypotheses were two sided with a type I error of 0.05 . No adjustments for multiple testing were made; only the primary BMI analysis could be considered confirmatory.

\section{Results}

\section{Patient disposition and characteristics}

A total of 203 patients were randomized and received the study drug (standard group $n=102$; intense group $n=101$ ) (Fig. 1). Of these, 82 patients $(40.4 \%)$ completed the study (standard group $n=45$ [44.1\%]; intense group $n=37$ [36.6\%]), with no significant difference between intervention groups regarding study completion or reasons for discontinuation. Median time to all-cause discontinuation was 238 days for the standard group and 211 days for the intense group ( $p=0.445$ ), with an estimated 6-month discontinuation rate of $47.1 \%$ for the standard group and $45.5 \%$ for the intense group. Adverse events were the most frequent reason for study discontinuation (standard group, $n=19$ [18.6\%]; intense group, $n=15$ [14.9\%]). Adverse events that lead to study discontinuation in more than one patient per weight intervention group were weight increase (standard group, $n=8$ [7.8\%]; intense group, $n=6[5.9 \%]$ ) and abnormal liver function (standard group, $n=2$ [2.0\%]; intense group, $n=0)$.

Patient characteristics at baseline are presented in Table 1 for the total group of patients, as well as by disease state and by randomized weight intervention group. Patients had a mean age of 15.8 years, were predominantly white $(80.8 \%)$, and had a roughly equal 


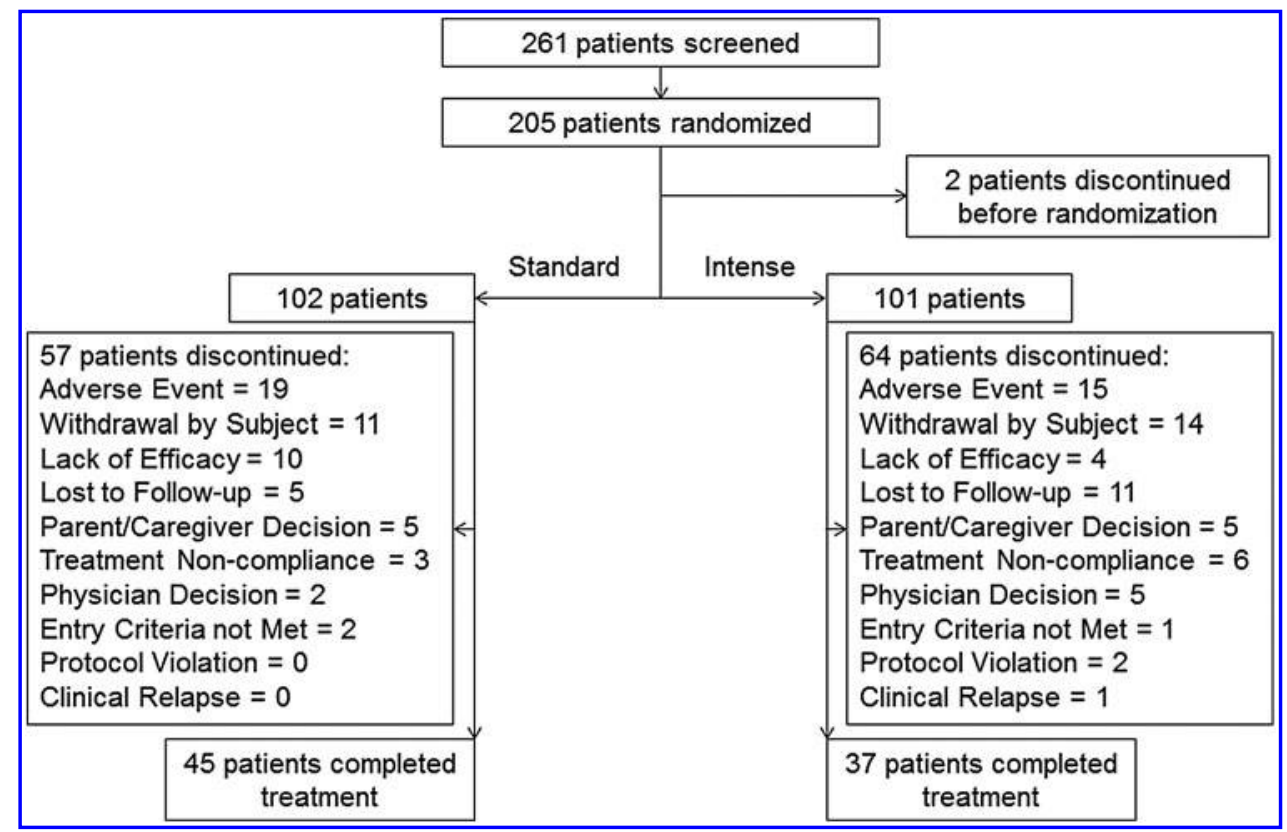

FIG. 1. Patient disposition. Note: Explanations for "Withdrawal by Subject" were as follows. Standard group: no additional comments provided $(n=3)$, change of residence $(n=2)$, excessive weight gain $(n=2)$, desire to start different medication $(n=1)$, lack of interest $(n=1)$, thinks to be cured $(n=1)$, refusal to follow protocol procedures $(n=1)$. Intense group: no additional comments provided $(n=4)$, desire to start different medication $(n=2)$, unhappy with medication $(n=1)$, lack of effect $(n=1)$, weight gain $(n=1)$, behavioral issues $(n=1)$, does not want to participate due to bloodwork $(n=1)$, unable to go to study visits $(n=1)$, change of residence $(n=1)$, thinks to be cured $(n=1)$.

Table 1. Baseline Demographic and Illness Characteristics by Disease State and by Weight Intervention Group

\begin{tabular}{|c|c|c|c|c|c|}
\hline Variable & $\begin{array}{c}\text { All } \\
\text { patients } \\
(\mathrm{N}=203)\end{array}$ & $\begin{array}{l}\text { Bipolar I } \\
\text { disorder } \\
(\mathrm{n}=116)\end{array}$ & $\begin{array}{l}\text { Schizophrenia } \\
\quad(\mathrm{n}=87)\end{array}$ & $\begin{array}{l}\text { Standard } \\
\text { group } \\
(\mathrm{n}=102)\end{array}$ & $\begin{array}{c}\text { Intense } \\
\text { group } \\
(\mathrm{n}=101)\end{array}$ \\
\hline Age (years), mean (SD) & $15.8(1.5)$ & $15.4(1.5)$ & $16.3(1.4)$ & $15.9(1.5)$ & $15.7(1.5)$ \\
\hline Male, $n(\%)$ & $106(52.2)$ & $51(44.0)$ & $55(63.2)$ & $52(51.0)$ & $54(53.5)$ \\
\hline Hispanic or Latino ethnicity, $n(\%)$ & $24(11.8)$ & $21(18.1)$ & $3(3.4)$ & $15(14.7)$ & $9(8.9)$ \\
\hline \multicolumn{6}{|l|}{ Race, $n(\%)$} \\
\hline American Indian or Alaska Native & $1(0.5)$ & 0 & $1(1.1)$ & 0 & $1(1.0)$ \\
\hline Asian & $3(1.5)$ & $3(2.6)$ & 0 & $2(2.0)$ & $1(1.0)$ \\
\hline Black or African American & $26(12.8)$ & $19(16.4)$ & $7(8.0)$ & $12(11.8)$ & $14(13.9)$ \\
\hline Multiple & $9(4.4)$ & $9(7.8)$ & 0 & $4(3.9)$ & $5(5.0)$ \\
\hline White & $164(80.8)$ & $85(73.3)$ & $79(90.8)$ & $84(82.4)$ & $80(79.2)$ \\
\hline \multicolumn{6}{|l|}{ Country of origin, $n(\%)$} \\
\hline Germany & $3(1.5)$ & 0 & $3(3.4)$ & $2(2.0)$ & $1(1.0)$ \\
\hline Poland & $18(8.9)$ & $3(2.6)$ & $15(17.2)$ & $6(5.9)$ & $12(11.9)$ \\
\hline Russian Federation & $55(27.1)$ & $2(1.7)$ & $53(60.9)$ & $28(27.5)$ & $27(26.7)$ \\
\hline United States & $127(62.6)$ & $111(95.7)$ & $16(18.4)$ & $66(64.7)$ & $61(60.4)$ \\
\hline BMI $\left(\mathrm{kg} / \mathrm{m}^{2}\right)$, mean $(\mathrm{SD})$ & $24.0(5.7)$ & $25.2(6.4)$ & $22.3(4.1)$ & $24.6(6.0)$ & $23.3(5.4)$ \\
\hline Weight $(\mathrm{kg})$, mean (SD) & $67.5(18.5)$ & $69.6(20.9)$ & $64.6(14.2)$ & $70.2(20.1)$ & $64.7(16.3)$ \\
\hline Waist circumference $(\mathrm{cm})$, mean $(\mathrm{SD})$ & $82.9(15.2)$ & $86.3(17.3)$ & $78.4(10.3)$ & $85.5(16.1)$ & $80.2(13.8)$ \\
\hline $\begin{array}{l}\text { Family history of obesity (first-degree } \\
\quad \text { relative), } n(\%)\end{array}$ & $62(30.5)$ & $54(46.6)$ & $8(9.2)$ & $33(32.4)$ & $29(28.7)$ \\
\hline YMRS total score, mean (SD) & NA & $23.2(6.4)$ & NA & $23.1(6.9)^{\mathrm{a}}$ & $23.3(5.8)^{\mathrm{b}}$ \\
\hline BPRS-C total score, mean (SD) & NA & NA & $45.4(10.1)$ & $44.2(10.3)^{\mathrm{c}}$ & $46.6(9.8)^{\mathrm{d}}$ \\
\hline CGI-S total score, mean (SD) & $4.5(0.7)$ & $4.4(0.6)$ & $4.7(0.7)$ & $4.5(0.7)$ & $4.5(0.6)$ \\
\hline Hospitalized during prior 12 months, $n(\%)$ & $106(52.2)$ & $53(45.7)$ & $53(60.9)$ & $51(50)$ & $55(54.5)$ \\
\hline
\end{tabular}

${ }^{\mathrm{a}} n=58$.

${ }^{\mathrm{b}} n=58$.

${ }^{\mathrm{c}} n=44$.

$\mathrm{d}_{n}=43$.

BMI, body mass index; BPRS-C, Brief Psychiatric Rating Scale for Children; CGI-S, Clinical Global Impression-Severity; NA, not applicable; SD, standard deviation; YMRS, Young Mania Rating Scale. 
gender distribution $($ male $=52.2 \%)$. A total of 87 patients $(42.9 \%)$ were diagnosed with schizophrenia (standard group, $n=44$; intense group, $n=43)$, and 116 patients $(57.1 \%)$ were diagnosed with bipolar I disorder ( $n=58$ for both groups), with the majority of patients with bipolar disorder coming from the United States and the majority of patients with schizophrenia coming from Russia. Across all patients, mean CGI-S score at baseline was 4.5 , indicating a moderately to markedly ill population. For the patients with schizophrenia, baseline BPRS-C total score was 45.4 , indicating an acutely psychotic population. For the patients with bipolar disorder, baseline YMRS total score was 23.2 , indicating an acutely manic population.

Comparison of weight intervention groups indicated some significant differences at baseline; patients in the standard group had a mean weight $\sim 5 \mathrm{~kg}$ heavier than the intense group (standard group, $70.2 \mathrm{~kg}$ [standard deviation, $\mathrm{SD}=20.1$ ]; intense group, $64.7 \mathrm{~kg}$ [16.3]) and a mean waist circumference $\sim 5 \mathrm{~cm}$ wider (standard

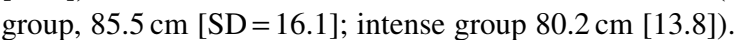

Median duration of exposure to olanzapine during the study was 219 days, with a mean daily dose of $10.75 \mathrm{mg}(\mathrm{SD}=5.08)$ and a median modal daily dose of $10 \mathrm{mg}$. No significant differences between weight intervention groups were observed with regard to drug exposure or dosing (standard group, median exposure $=226$ days, mean daily dose $=10.52 \mathrm{mg}[\mathrm{SD}=5.04]$; intense group, median exposure $=219$ days, mean daily dose $=10.98 \mathrm{mg}[\mathrm{SD}=5.13]$ ).

\section{Effectiveness of weight interventions}

No statistically significant differences between the standard and the intense groups were observed in overall mean change in BMI ( $p=0.134$ ) or in least squares (LS) mean change in BMI at any study visit (Fig. 2a). LS mean change in BMI from baseline to 52 weeks was $3.64 \mathrm{~kg} / \mathrm{m}^{2}$ (standard error $[\mathrm{SE}]=0.39$ ) for the standard group and $2.83 \mathrm{~kg} / \mathrm{m}^{2}(\mathrm{SE}=0.40)$ for the intense group $(p=0.150)$. Baseline to LOCF endpoint evaluation of mean changes in patients treated for at least 6 months also did not result in statistically significant differences between weight intervention groups in increases in BMI (standard group, $3.36 \mathrm{~kg} / \mathrm{m}^{2}$ [SE $=0.41$ ]; intense group $2.99 \mathrm{~kg} / \mathrm{m}^{2}$ [0.40]; $p=0.520$ ). Distribution of changes in BMI (Fig. 2b) indicated that a majority of patients (standard group, $82 \%$; intense group, $75 \%$ ) had greater increases than would be expected through normal adolescent growth (i.e., greater than approximately half a unit of BMI per year). However, there were some patients whose BMI stayed the same or decreased (standard group, 9\%; intense group, 15\%).

There were no significant differences between weight interventions with regard to mean change in bodyweight (Fig. 2c), and both weight intervention groups showed clinically significant mean increases in weight throughout the study (all within-group $p$-values $<0.001)$. From baseline to 52 weeks, patients experienced an LS mean change in weight of $12.05 \mathrm{~kg}(\mathrm{SE}=1.16)$ in the standard group and $9.63 \mathrm{~kg}(\mathrm{SE}=1.20)$ in the intense group $(p=0.148)$. Among patients treated for at least 6 months, mean change in weight from baseline to LOCF endpoint was also high but with no significant difference between intervention groups (standard group, $10.97 \mathrm{~kg}$ [SE=1.21]; intense group, $9.82 \mathrm{~kg}$ [1.19]; $p=0.495)$.

A majority of patients in both intervention groups gained $\geq 7 \%$ of their baseline weight at endpoint (Fig. 3): 56.9\% in the standard group and $63.4 \%$ in the intense group. No significant differences were observed between the weight intervention groups at any time or at endpoint for any categories of potentially clinically significant weight changes, although there was a numeric trend at the higher degrees of weight gain, with numerically fewer patients in the intense group gaining $\geq 15 \%$ or $\geq 25 \%$ of their baseline bodyweight at any time or at endpoint than in the standard group. For example, the percentage of patients at endpoint who gained $\geq 15 \%$ of their baseline weight was $40 \%$ for the standard group and $31 \%$ for the intense group ( $p=0.187)$.

There were no significant differences between interventions with regard to mean change in waist circumference. From baseline to 52 weeks, LS mean change in waist circumference was $7.2 \mathrm{~cm}(\mathrm{SE}=1.1)$ in the standard group and $7.3 \mathrm{~cm}(\mathrm{SE}=1.1)$ in the intense group $(p=0.954)$.

Subgroup analyses were conducted to examine whether the weight interventions had differential effects on BMI or weight based on gender, disease state, race, or geographical region. No statistically significant intervention effect was found within any of the subgroups on either measure, and there were no statistically significant interactions between any subgroups and the intervention. However, a statistically significant difference was noted between boys and girls with respect to the relationship between weight intervention and the adverse event of "increased weight" $(p=0.028)$; male patients in the standard group were somewhat less likely to have weight increase reported as an adverse event than those in the intense group ( $15 \%$ vs. $20 \%$ ), whereas female patients in the standard group were more likely to have weight increase reported as an adverse event than those in the intense group (46\% vs. $21 \%$ ). This finding would appear to suggest that female patients were more likely to benefit from the intense weight intervention program than were male patients. There was also some evidence with respect to the disease state groups $(p=0.066)$; patients with schizophrenia in the standard group were somewhat less likely to experience increased weight than those in the intense group $(11 \%$ vs. $16 \%$ ), whereas patients with bipolar disorder in the standard group were more likely to experience increased weight than those in the intense group ( $45 \%$ vs. $24 \%$ ). These two findings are likely confounded as there were more male patients with schizophrenia.

\section{Treatment effectiveness}

Across all patients, all disease state effectiveness measures demonstrated significant mean improvement at 3-4 days and at all subsequent visits, with improvement increasing throughout the trial (Figs. 4, and 5a, b). Patients with bipolar disorder in the intense group showed less improvement than in the standard group on both the YMRS (overall $p=0.018$ ) and the CGI-S (overall $p=0.016$ ). There was no such interaction between disease state effectiveness and weight intervention among the patients with schizophrenia.

\section{Safety and tolerability}

Adverse events. A total of 162 patients (79.8\%) experienced at least one treatment-emergent adverse event during the study (Table 2). The most frequently reported adverse events were weight increase, somnolence, and headache, with no significant differences between weight intervention groups. Weight increase was reported as an adverse event in $30.4 \%$ of patients in the standard group and $20.8 \%$ of patients in the intense group $(p=0.148)$. A total of 33 $(16.3 \%)$ patients experienced serious adverse events (SAEs) (standard group, $12.7 \%$; intense group, $19.8 \% ; p=0.188$ ), with most events being related to disease state. The SAEs occurring in more than one patient in the standard group were suicidal ideation (three patients [2.9\%]) and suicide attempt (two patients [2.0\%]). The SAEs occurring in more than one patient in the intense group were psychotic disorder (four patients [4.0\%]), suicidal ideation (two patients [2.0\%]), and bipolar disorder/bipolar I disorder (six patients [5.9\%]). Only the SAE rate of bipolar disorder/bipolar I disorder was 

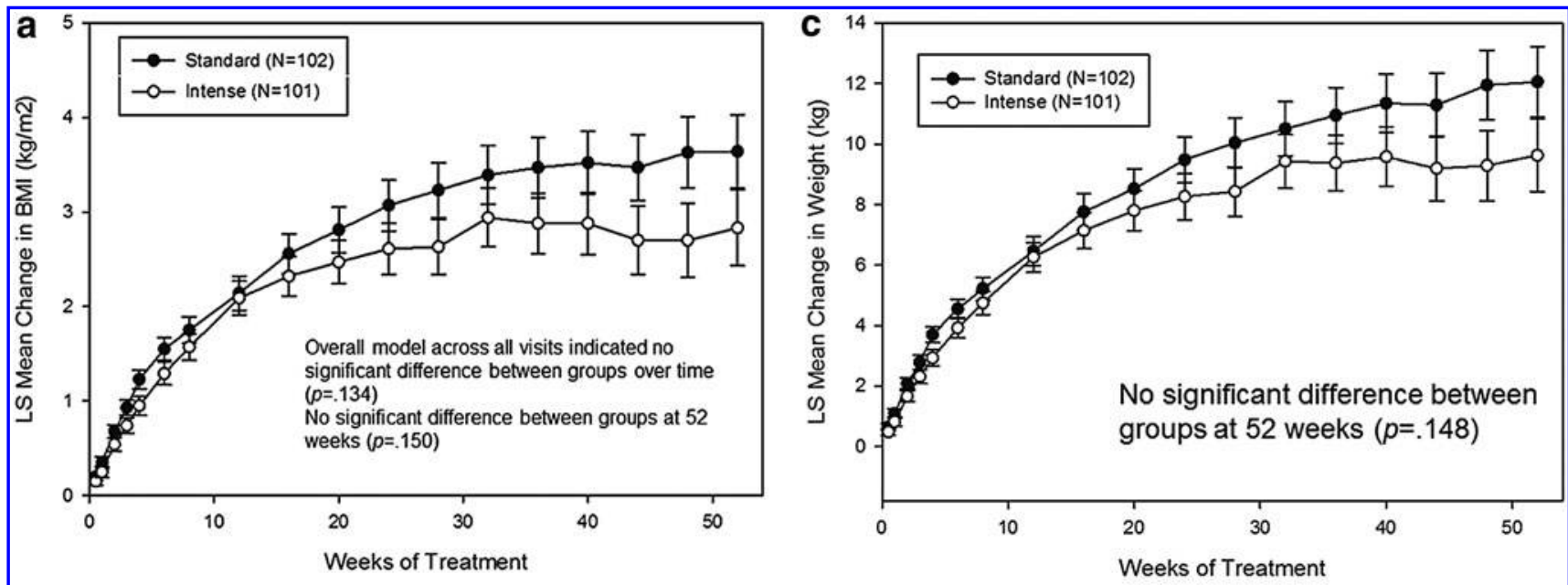

b

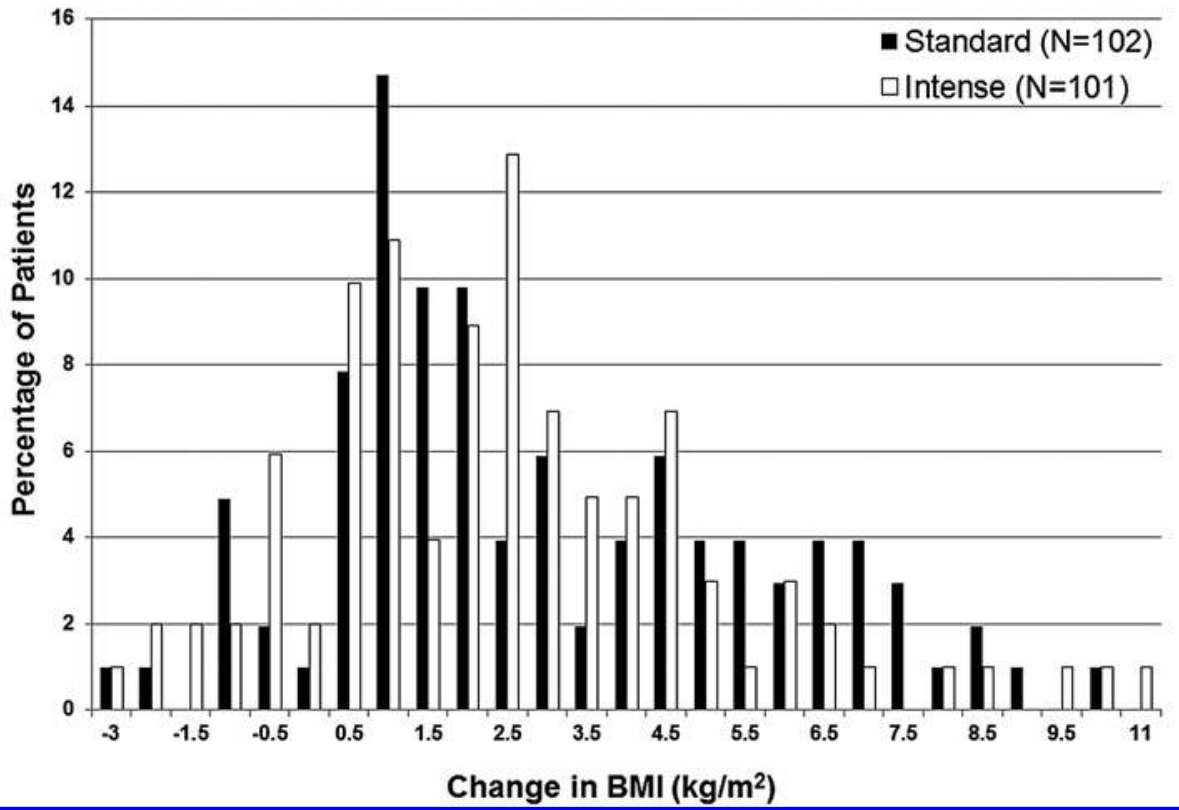

FIG. 2. (a) LS mean changes in BMI over time for patients receiving a standard or intense behavioral weight counseling intervention (MMRM analysis). (b) Percentage of patients experiencing change from baseline to LOCF endpoint in BMI for patients receiving a standard or intense behavioral weight counseling intervention. (c) LS mean changes in weight over time for patients receiving a standard or intense behavioral weight counseling intervention (MMRM analysis). BMI, body mass index; LOCF, last observation carried forward; LS, least squares; MMRM, mixed model repeated measures; $N$, number of patients. Error bars indicate standard error.

significantly different between intervention groups $(p=0.014)$. All other SAEs were reported by one patient each and were mostly disease state related, with a notable exception of a single case of neuroleptic malignant syndrome. No deaths occurred.

Laboratory analytes. No significant differences between weight intervention groups were observed with regard to mean changes from baseline to LOCF endpoint in any laboratory analytes (Table 3). Figure 6 presents mean changes in the total group of patients over time in select analytes using MMRM methodology. Mean prolactin levels for the total group of patients indicated a transient increase at week 6 but a subsequent decrease below baseline starting at week 16 through week 52. A transient increase early in treatment was also noted for alanine aminotransferase. Categorical changes in metabolic analytes and prolactin at any time and at endpoint are presented in Figure 7.
ECG and vital signs. Patients in the standard group experienced a significantly greater LS mean increase from baseline in heart rate compared with patients in the intense group $(p<0.001$; Table 3). There was no significant difference between intervention groups in Fridericia-corrected QT interval (QTcF). No patients experienced a $\mathrm{QTcF} \geq 450$ milliseconds at any time, and no patients experienced an increase in $\mathrm{QTcF} \geq 60$ milliseconds at any time. Patients in the standard group showed clinically small mean increases in blood pressure (statistically significant differences from intense group for supine diastolic [ $p=0.017]$ and standing systolic $[p=0.031]$ blood pressure), whereas patients in the intense group demonstrated little to no mean change (Table 3).

Extrapyramidal symptoms. Mean baseline scores for all three indices of EPS were low. Postbaseline mean changes were small and not clinically significant. Among the total group of 


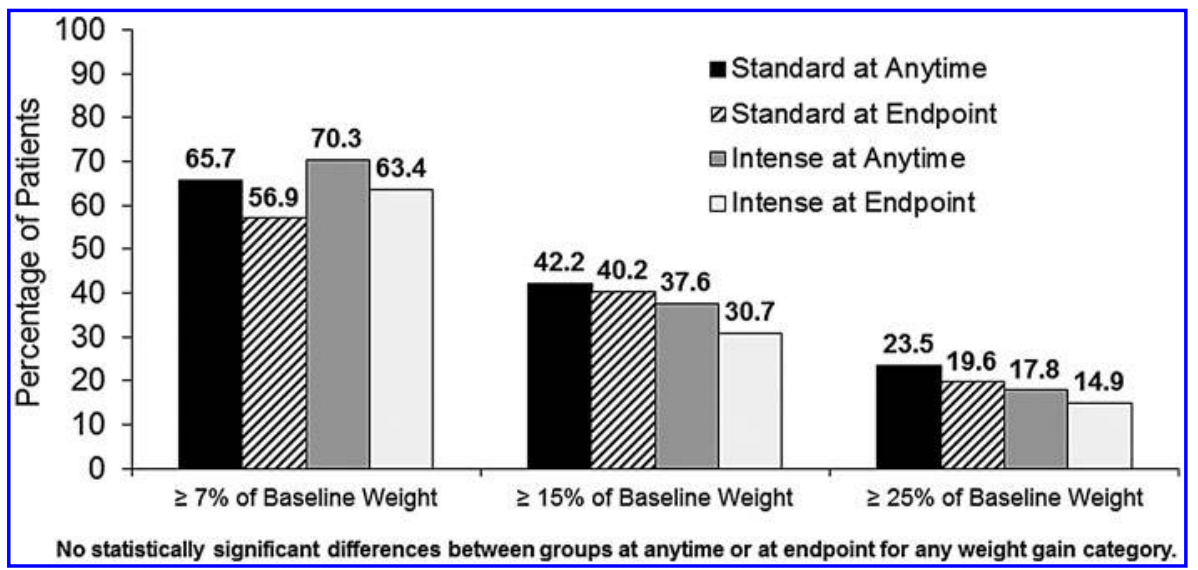

FIG. 3. Percentage of patients in the standard and intense behavioral weight counseling intervention groups with potentially clinically significant increases in weight at any time and at endpoint.

patients, the incidences of treatment-emergent akathisia (score of $\geq 2$ in patients who had a score of $<2$ at baseline on the Barnes Akathisia Scale), parkinsonism (score of $>3$ in patients who had a score of $\leq 3$ at baseline on the SAS), and dyskinesia (AIMS single items score of $\geq 3$, or $\geq 2$ item scores $\geq 2$ with all single item scores $<3$ and $\geq 6$ item scores $<2$ at baseline) were $8.9 \%, 5.8 \%$, and $1.1 \%$, respectively, at any time, and $3.4 \%, 2.6 \%$, and $1.1 \%$, respectively, at endpoint. No significant differences between weight intervention groups for any of these treatment-emergent events were observed.

Suicidality. Based on the C-SSRS, 27 patients (13.3\%) displayed suicidal ideation during the study (standard group, $17.6 \%$; intense group, $8.9 \%$ ), and 6 patients (3.0\%) exhibited suicidal behavior (standard group, $4.9 \%$; intense group, $1.0 \%$ ). No completed suicides occurred.

\section{Discussion}

This study evaluated the 1-year safety and tolerability of olanzapine (2.5-20 mg/day) in adolescent patients with schizophrenia or bipolar I disorder with manic or mixed episodes. The study also evaluated the effectiveness of an intense behavioral weight intervention (consisting of regular diet and lifestyle counseling sessions) to see whether such an intervention would be superior to a standard behavioral weight counseling intervention (consisting of a single counseling session) with respect to mitigation of weight gain.

\section{Behavioral weight counseling intervention}

Results indicated that patients in both groups gained a substantial amount of weight over the course of 1 year, with a majority of patients gaining $\geq 7 \%$ of their baseline weight. Patients randomized to the intense intervention had, on average, numerically smaller changes on weight-related measures (LS mean changes in BMI and weight; categorical changes in BMI and weight; treatment-emergent adverse events related to weight) relative to those patients who were randomized to the standard intervention, but none of these differences was statistically significant.

To put the current findings into context, results of weight mitigation programs are typically modest at best, particularly when the

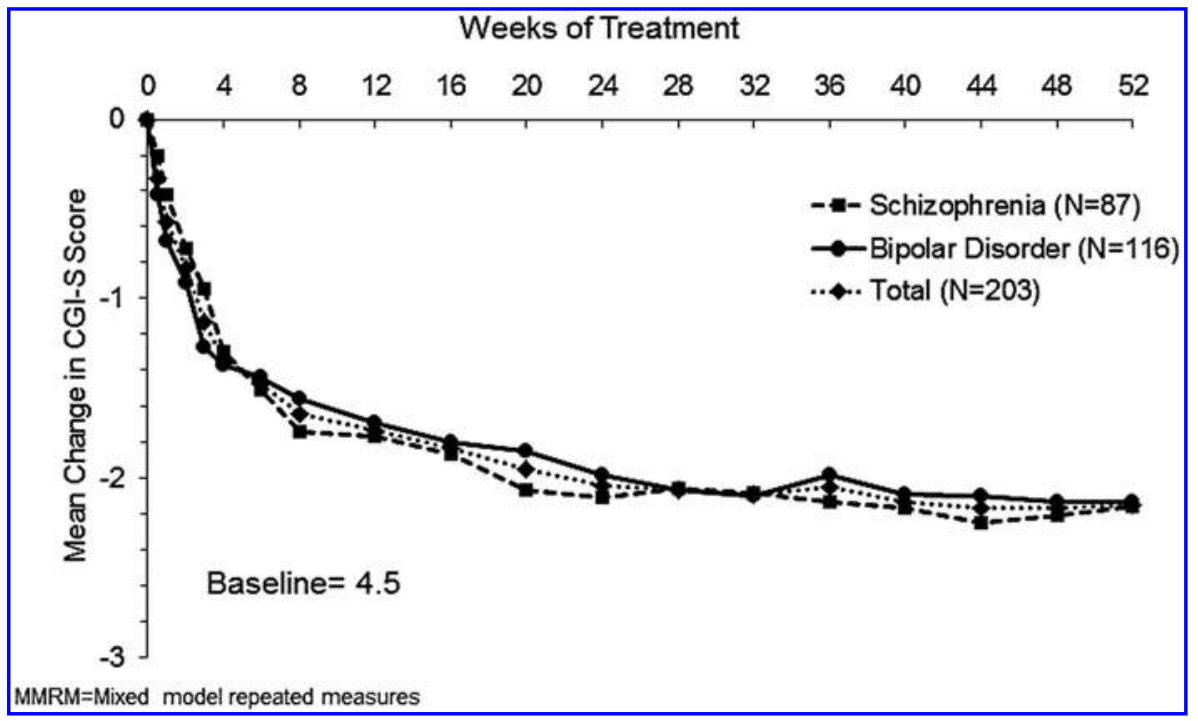

FIG. 4. Mean changes in CGI-S for the total group of patients and by disease state (MMRM analysis). CGI-S, Clinical Global Impression-Severity; MMRM, mixed model repeated measures; $N$, number of patients. 


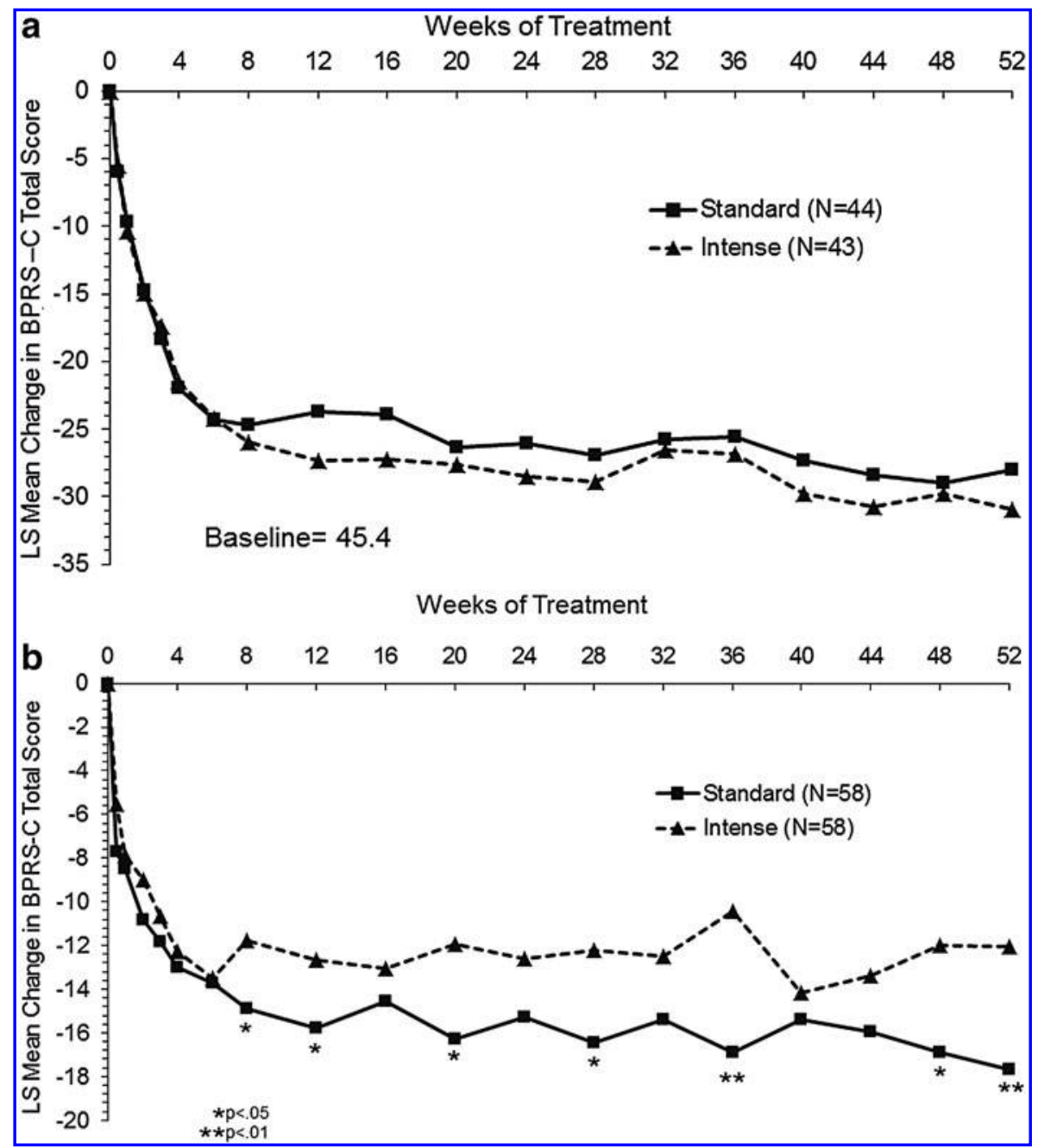

FIG. 5. Mean changes in symptom ratings over time for patients receiving a standard or intense behavioral weight counseling intervention (MMRM analysis). (a) Patients with schizophrenia, as rated on the BPRS-C. (b) Patients with bipolar disorder, as rated on the YMRS. BPRS-C, Brief Psychiatric Rating Scale for Children; LS, least squares; MMRM, mixed model repeated measures; $N$, number of patients; YMRS, Young Mania Rating Scale. $* p<0.05, * * p<0.01$.

Table 2. Treatment-Emergent Adverse Events in $\geq 5 \%$ of All Patients, by Weight Intervention Group

\begin{tabular}{|c|c|c|c|c|}
\hline & $\begin{array}{c}\text { All patients } \\
(\mathrm{N}=203), \mathrm{n}(\%)\end{array}$ & $\begin{array}{l}\text { Standard group } \\
(\mathrm{n}=102), \mathrm{n}(\%)\end{array}$ & $\begin{array}{l}\text { Intense group } \\
(\mathrm{n}=101), \mathrm{n}(\%)\end{array}$ & $\mathrm{p}-$ Value $^{\mathrm{a}}$ \\
\hline Any adverse event & $162(79.8)$ & $81(79.4)$ & $81(80.2)$ & $>0.999$ \\
\hline Weight increased & $52(25.6)$ & $31(30.4)$ & $21(20.8)$ & 0.148 \\
\hline Somnolence & $43(21.2)$ & $19(18.6)$ & $24(23.8)$ & 0.395 \\
\hline Headache & $39(19.2)$ & $19(18.6)$ & $20(19.8)$ & 0.860 \\
\hline Increased appetite & $29(14.3)$ & $16(15.7)$ & $13(12.9)$ & 0.689 \\
\hline Nasopharyngitis & $25(12.3)$ & $14(13.7)$ & $11(10.9)$ & 0.670 \\
\hline Blood insulin increased & $17(8.4)$ & $10(9.8)$ & $7(6.9)$ & 0.614 \\
\hline Fatigue & $15(7.4)$ & $9(8.8)$ & $6(5.9)$ & 0.593 \\
\hline $\begin{array}{l}\text { Blood creatine phosphokinase } \\
\text { increased }\end{array}$ & $12(5.9)$ & $7(6.9)$ & $5(5.0)$ & 0.767 \\
\hline Sedation & $11(5.4)$ & $8(7.8)$ & $3(3.0)$ & 0.214 \\
\hline Vomiting & $11(5.4)$ & $7(6.9)$ & $4(4.0)$ & 0.537 \\
\hline
\end{tabular}

${ }^{\mathrm{a}} p$-Values are based on a Fisher exact test comparing two intervention groups.

$N$, total number of patients; $n$, number of affected patients. 
Table 3. Mean Changes from Baseline to Endpoint in Laboratory Analytes, Electrocardiograms, and Blood Pressure by Weight Intervention Group (Last Observation Carried Forward)

\begin{tabular}{|c|c|c|c|c|}
\hline & Analyte & $\begin{array}{c}\text { Standard group } \\
(\mathrm{N}=102), \\
\text { LS mean change }(S E)\end{array}$ & $\begin{array}{c}\text { Intense group } \\
(\mathrm{N}=101), \\
\text { LS mean change }(S E)\end{array}$ & $\mathrm{p}-$ Value $e^{\mathrm{a}}$ \\
\hline Hepatic laboratory measures & $\begin{array}{l}\text { ALT (U/L) } \\
\text { AST (U/L) } \\
\text { GGT (U/L) } \\
\text { Total bilirubin (umol/L) }\end{array}$ & $\begin{array}{r}5.6(1.8) \\
2.3(1.0) \\
3.4(1.6) \\
-1.1(0.3)\end{array}$ & $\begin{array}{r}2.0(1.8) \\
0.2(1.0) \\
0.1(1.6) \\
-1.4(0.3)\end{array}$ & $\begin{array}{l}0.158 \\
0.121 \\
0.136 \\
0.410\end{array}$ \\
\hline $\begin{array}{l}\text { Metabolic laboratory measures } \\
\text { (fasting) }\end{array}$ & $\begin{array}{l}\text { Glucose }(\mathrm{mmol} / \mathrm{L}) \\
\text { Total cholesterol }(\mathrm{mmol} / \mathrm{L}) \\
\text { HDL cholesterol }(\mathrm{mmol} / \mathrm{L}) \\
\text { LDL cholesterol }(\mathrm{mmol} / \mathrm{L}) \\
\text { Triglycerides }(\mathrm{mmol} / \mathrm{L})\end{array}$ & $\begin{aligned} 0.1 & (0.1) \\
0.04 & (0.1) \\
-0.1 & (0.02) \\
0.1 & (0.1) \\
0.3 & (0.1)\end{aligned}$ & $\begin{aligned} & 0.1(0.1) \\
&-0.02(0.1) \\
&-0.1(0.02) \\
& 0.0(0.1) \\
& 0.4(0.1)\end{aligned}$ & $\begin{array}{l}0.724 \\
0.486 \\
0.206 \\
0.390 \\
0.279\end{array}$ \\
\hline Endocrine laboratory measures & $\begin{array}{l}\text { Insulin }(\mu \mathrm{IU} / \mathrm{mL}) \\
\text { Prolactin }(\mu \mathrm{g} / \mathrm{L})\end{array}$ & $\begin{array}{r}5.0(2.4) \\
-1.7(1.1)\end{array}$ & $\begin{array}{r}7.3(2.4) \\
-0.6(1.1)\end{array}$ & $\begin{array}{l}0.489 \\
0.501\end{array}$ \\
\hline Hematologic laboratory measures & $\begin{array}{l}\text { Leukocytes (bill/L) } \\
\text { Neutrophils (bill/L) }\end{array}$ & $\begin{array}{l}-0.1(0.2) \\
-0.2(0.2)\end{array}$ & $\begin{array}{l}-0.3(0.2) \\
-0.4(0.2)\end{array}$ & $\begin{array}{l}0.560 \\
0.322\end{array}$ \\
\hline Electrocardiogram & $\begin{array}{l}\text { Heart rate (bpm) } \\
\text { QTcF (milliseconds) }\end{array}$ & $\begin{array}{l}7.7(1.3) \\
0.9(1.6)\end{array}$ & $\begin{array}{l}1.3(1.3) \\
2.0(1.6)\end{array}$ & $\begin{array}{r}<0.001 \\
0.635\end{array}$ \\
\hline Blood pressure & $\begin{array}{l}\text { Supine systolic }(\mathrm{mm} \mathrm{Hg}) \\
\text { Supine diastolic }(\mathrm{mm} \mathrm{Hg}) \\
\text { Standing systolic }(\mathrm{mm} \mathrm{Hg}) \\
\text { Standing diastolic }(\mathrm{mm} \mathrm{Hg})\end{array}$ & $\begin{array}{l}2.5(1.1) \\
2.4(0.8) \\
3.7(1.0) \\
1.0(0.9)\end{array}$ & $\begin{array}{r}0.5(1.1) \\
-0.4(0.8) \\
0.6(1.0) \\
-0.2(0.9)\end{array}$ & $\begin{array}{l}0.185 \\
0.017 \\
0.031 \\
0.318\end{array}$ \\
\hline
\end{tabular}

${ }^{\mathrm{a} B e t w e e n ~ i n t e r v e n t i o n ~ g r o u p ~} p$-values for LS mean changes.

ALT, alanine aminotransferase; AST, aspartate aminotransferase; GGT, gamma glutamyl transferase; HDL, high-density lipoprotein; LDL, lowdensity lipoprotein; LS, least squares; LOCF, last observation carried forward; QTcF, Fridericia-corrected QT interval; SE, standard error.

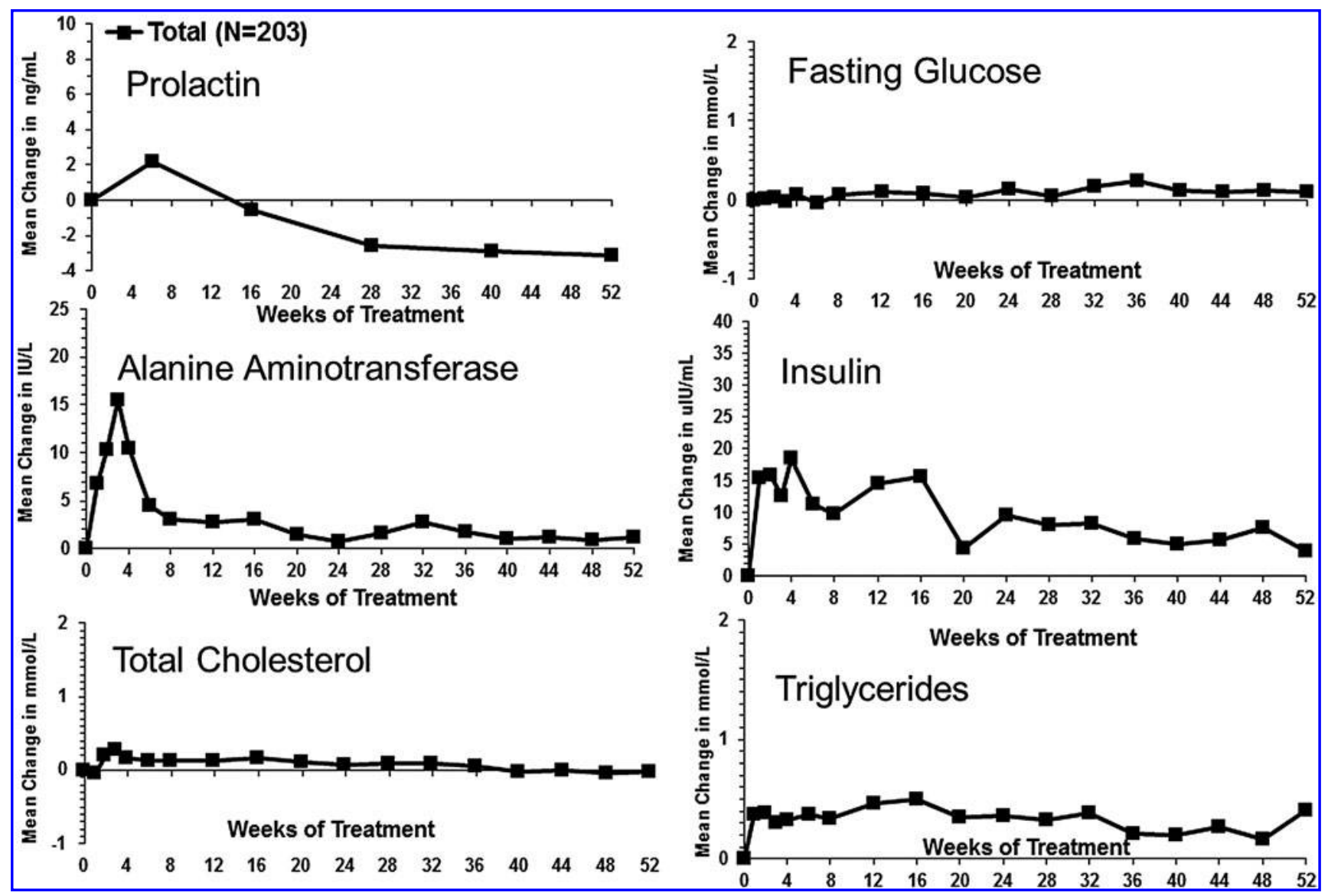

FIG. 6. Mean changes over time in select laboratory analytes for the total group of patients (MMRM analysis). MMRM, mixed model repeated measures. 


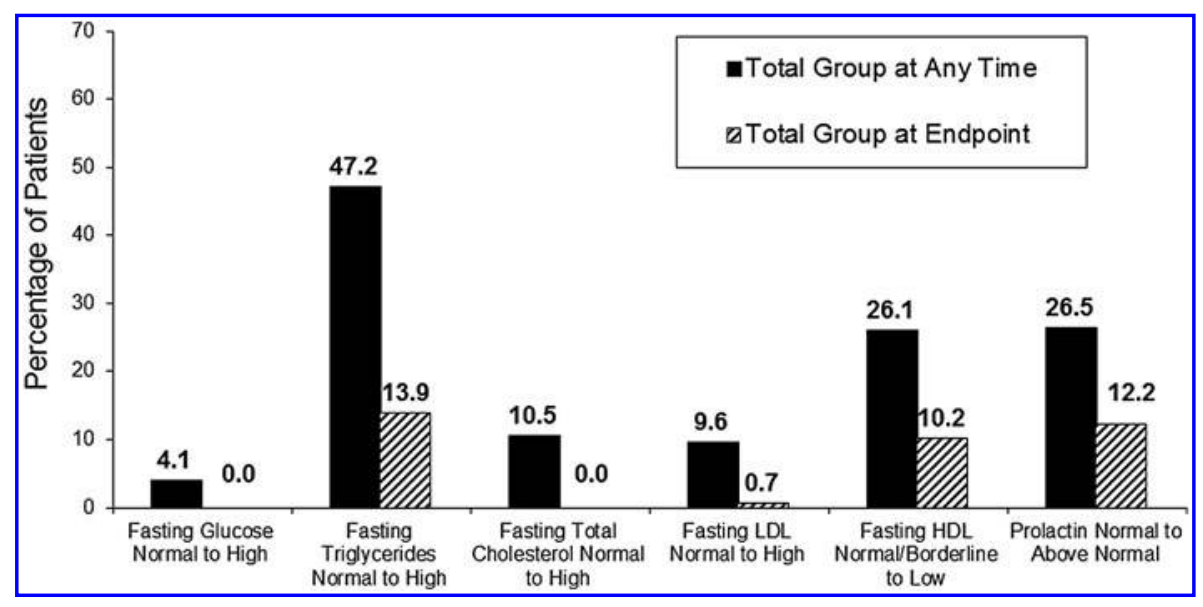

FIG. 7. Percentage of all patients with potentially clinically significant changes in select laboratory analytes at any time and at endpoint. Potentially clinically significant definitions: fasting glucose $\geq 7 \mathrm{mmol} / \mathrm{L}$ following baseline of $<5.6 \mathrm{mmol} / \mathrm{L}$; fasting triglycerides $\geq 1.5 \mathrm{mmol} / \mathrm{L}$ following baseline of $<1.0 \mathrm{mmol} / \mathrm{L}$; total fasting cholesterol $\geq 5.2 \mathrm{mmol} / \mathrm{L}$ following baseline of $<4.4 \mathrm{mmol} / \mathrm{L}$; fasting $\mathrm{LDL} \geq 3.4 \mathrm{mmol} / \mathrm{L}$ following baseline of $<2.8 \mathrm{mmol} / \mathrm{L}$; fasting $\mathrm{HDL}<0.9 \mathrm{mmol} / \mathrm{L}$ following baseline of $\geq 0.9 \mathrm{mmol} / \mathrm{L}$; prolactin $>20 \mathrm{ng} / \mathrm{mL}$ for males or $>29 \mathrm{ng} / \mathrm{mL}$ for females (ADA and NCEP criteria effective 2001). There were no significant differences between the standard and intense intervention groups in categorical metabolic or prolactin changes at any time or at endpoint. ADA, American Diabetes Association; HDL, high-density lipoprotein; LDL, low-density lipoprotein; NCEP, National Cholesterol Education Program.

intervention is of a counseling or educational nature and does not require actual dieting or exercise but only counsels toward it (Poulin et al. 2007). Moreover, not all such programs in adults have resulted in statistically significant differences in weight, even when a multimodal approach was used (Usher et al. 2013; Cordes et al. 2014). Systematic reviews of childhood obesity prevention programs in the general population of overweight children found that none of the home-based programs resulted in change in weight-related outcomes (Showell et al. 2013) and few of the community-based programs resulted in such changes (Bleich et al. 2013). Programs that were more successful were for younger aged children and included a school-based component (Bleich et al. 2013).

With respect to programs similar to those of the present study but done in adults, Daumit et al. (2013) conducted a behavioral weight intervention versus a negative control intervention in mentally ill adults (predominantly patients with schizophrenia and bipolar disorder). The mean difference in weight change between the behavioral weight intervention versus a negative control intervention group was $-1.5,-2.5$, and $-3.2 \mathrm{~kg}$, at 6,12 , and 18 months, respectively. The magnitude of 1-year difference between groups in that adult study $(2.5 \mathrm{~kg})$ is thus similar to the magnitude of difference in the present adolescent study $(2.42 \mathrm{~kg}$ ). Daumit et al. (2013) considered the observed weight differences to be modest but clinically relevant.

\section{Overall safety and tolerability}

Considering the long-term safety and tolerability findings for olanzapine across the total group of patients, results were generally consistent with the known profile of olanzapine in adolescent patients observed in previous studies (Kryzhanovskaya et al. 2009b), with some differences that could be attributed to the longer duration of the current study and/or to the use of the behavioral weight intervention. Although patients in the current study could receive treatment with olanzapine for up to 52 weeks, the maximum duration of any of the pooled trials in the Kryzhanovskaya et al. (2009b) database was 32 weeks. Otherwise, the two populations were comparable in terms of demographics, disease state composition, and olanzapine dosing.
Changes in weight and BMI were in line with the Kryzhanovskaya et al. (2009b) results, although they were slightly higher in the standard group at the end of 52 weeks relative to the other studies' 32 week result, which was consistent with longer treatment exposure. The most notable difference was that patients in the current study showed an overall mean decrease in prolactin from baseline, with fewer patients developing treatment-emergent abnormally high prolactin compared with previous adolescent olanzapine studies (Kryzhanovskaya et al. 2009b). However, the overall visit-wise pattern of mean changes in prolactin appeared consistent with the pattern observed in the previous studies.

In the current study, only five patients experienced adverse events that could have been related to changes in prolactin (two cases of amenorrhea, one case of breast pain and acne, and one case of dysmenorrhea), all of which were rated as mild in severity. In both the current study and the previous studies, prolactin levels peaked at week 6 and decreased thereafter (Kryzhanovskaya et al. 2009b), although in the current study, the prolactin levels continued to decrease below baseline levels on average. No apparent explanation for this difference from previous studies could be found because baseline prolactin levels and previous medication usage were similar across trials.

\section{Disease state effectiveness}

Although the current study was an open-label, uncontrolled study, results are supportive of the effectiveness of olanzapine in the acute and long-term treatment of adolescents with schizophrenia or bipolar I disorder (manic or mixed episodes). All measures of clinical disease state effectiveness demonstrated significant improvement from baseline as early as 3-4 days of treatment, with improvements continuing for the remainder of the 52-week trial. Results were comparable to those from the acute and open-label extension phases of a prior study of olanzapine in adolescents with bipolar mania (Tohen et al. 2007; McCormack 2010), as well as of a prior study of olanzapine in adolescents with schizophrenia (Kryzhanovskaya et al. 2009a; McCormack 2010).

Interestingly, patients with bipolar disorder assigned to the intense intervention showed somewhat less improvement in their 
symptom scores and were also more likely to have exacerbated symptoms than those assigned to the standard weight intervention. In contrast, no significant difference between the weight intervention groups with respect to schizophrenia disease state effectiveness was observed. Although there is no clear explanation for this finding, one possibility is that patients with a mood disorder and depressive tendencies may have been more likely to perceive the intense intervention as aversive or stressful, with a perceived focus on body image and implied expectations, thus possibly interfering with psychological symptom improvements due to certain disease characteristics, such as low self-esteem (Pavlickova et al. 2013). Another possibility was whether the increased focus on weight may have resulted in greater self-dissatisfaction in the patients with bipolar disorder, which in turn may have led to poorer treatment compliance in some patients in an attempt to minimize weight gain and could then have affected treatment effectiveness.

\section{Limitations}

There are several limitations to the current study. With regard to disease state effectiveness, the open-label uncontrolled design limits the ability to draw strong conclusions about effectiveness. Nevertheless, this more naturalistic design is appropriate for the long-term evaluation of a medication and provides results that may be more generalizable to standard clinical practice. With regard to the behavioral weight intervention, it is important to acknowledge that the interventions were office-based counseling programs that did not require actual changes in patients' diet and exercise behaviors. Although patients were to keep track of their nutritional intake and physical activity in daily logs, these data were not formally collected for data analysis, and no information was collected from parents or caregivers to attempt to quantify patients' actual level of adherence to the recommendations from the counseling sessions.

Other limitations include the baseline differences between the disease state populations and the possible confounding of disease state and geographical region. The patients with bipolar disorder were heavier at baseline and more likely to have a family history of obesity and metabolic disorders. At the same time, there was significant overlap between disease state and region as most of the patients with bipolar disorder were from the United States. Thus, it is difficult to determine whether differences between the disease state groups can be attributed to the disease state or to cultural differences between regions. Overall, those comparisons should not be made as the study was not designed for comparisons between disease states but between weight interventions.

Finally, there was a notably high study discontinuation rate observed $(59.6 \%)$ in the current study. Although this rate is generally consistent with what has been observed in other studies of antipsychotic usage in children and adolescents-for example, Noguera et al. (2013) report a 1-year discontinuation rate of $59.1 \%$ in their sample of 9- to 17-year-old first episode psychosis patients treated with an antipsychotic - this high discontinuation could be considered a limitation when interpreting the long-term study results. Although the statistical methods used in the current analyses do account for patient discontinuation over time, it is important to acknowledge that large amounts of missing data may challenge these assumptions.

\section{Conclusions}

Tolerability and safety results of the current study were generally similar to those of previous adolescent studies, although changes in prolactin and hepatic analytes were less notable. No new safety signals were identified during this long-term study. Thus, the findings from this study do not change the overall benefit-risk profile of olanzapine in adolescents. Because the early onset of schizophrenia or bipolar disorder is frequently associated with a more severe course and poorer prognosis, olanzapine remains an important treatment option for adolescents with schizophrenia or bipolar disorder with manic or mixed episodes. The overall benefitrisk profile in this patient population thus remains positive.

With regard to the benefit-risk profile of the standard and intense behavioral weight interventions, results of this study did not demonstrate a statistically significant difference between the two interventions. Small but generally consistent numeric differences between the groups suggest that individual patients may have gained some benefit from the program. There appeared to be little safety risk to using the program, although there was less improvement of psychiatric state in the patients with bipolar disorder who were exposed to the intense intervention. Thus, as implemented in the current study, the overall benefit-risk profile for the weight intervention program appears neutral in this population.

Results of the current study extend the data on olanzapine in adolescents to 52-week treatment/observations and offer further supportive evidence of both the acute and long-term effectiveness of olanzapine in the treatment of schizophrenia and bipolar and mixed mania in adolescents. This benefit must be weighed against the risks observed in adolescent patients treated with olanzapine, including weight gain and metabolic changes. It is recommended that all patients treated with olanzapine receive regular monitoring of weight, lipids, and glucose to help manage these risks.

\section{Clinical Significance}

The tolerability and safety of olanzapine for up to 52 weeks in patients aged 13-17 years diagnosed with schizophrenia or bipolar I disorder were generally similar to that observed previously in adolescent patients treated for up to 32 weeks with olanzapine. The most notable difference was that patients in the current study showed an overall mean decrease in prolactin from baseline to endpoint, with fewer patients developing treatment-emergent abnormally high prolactin compared with previous adolescent olanzapine studies. No statistically significant differences in BMI or other weight-related changes were observed between standard and intense weight intervention, although small numerical differences were generally observed in favor of the intense intervention.

\section{Acknowledgments}

The authors thank the patients, parents/guardians, and investigators who participated in this clinical trial. The authors also thank Angela Lorio, a full-time employee of inVentiv Health Clinical, LLC, for editorial assistance. Eli Lilly and Company contracted inVentiv Health Clinical, LLC, for editorial and writing services. Statistical consultant: John Landry, MMath, Eli Lilly Canada, Danforth, Ontario, Canada. Clinical Trial Registry Number (www. ClinicalTrials.gov): NCT00982020.

\section{Disclosures}

Drs. Detke and Hoffmann and Mr. Landry are full-time employees and stockholders of Eli Lilly and Company. Dr. Dittmann has received compensation for serving as consultant or speaker, or he or the institution he works for has received research support or royalties from the following companies or organizations: EU (FP7 Programme), US National Institute of Mental Health (NIMH), German Federal 
Ministry of Health/Regulatory Agency (BMG/BfArM), German Federal Ministry of Education and Research (BMBF), German Research Foundation (DFG), Volkswagen Foundation, Boehringer Ingelheim, Ferring, Janssen-Cilag, Eli Lilly and Company, Lundbeck, Otsuka/Takeda, Servier, Shire, and Theravance. Dr. Dittmann owns Eli Lilly and Company stock. Dr. DelBello received research support from Eli Lilly and Company, Otsuka, Merck, Novartis, Lundbeck, Shire, Purdue, Amylin, Sunovion, Pfizer, Supernus, and Amarex; she is consulting, a member of the Advisory Board, received Honoraria and Travel reimbursement from Pfizer, Dey, Lundbeck, Sunovion, Otsuka, Supernus, Forest, and Actavis. Dr. Heinloth is a full-time employee of inVentiv Health, LLC. Eli Lilly and Company contracted inVentiv Health for writing and editorial services. Mr. Landry analyzed the data, and the first draft of the manuscript was written by Dr. Heinloth and critically revised and approved by all authors.

\section{References}

Alvarez-Jimenez M, Hetrick SE, Gonzalez-Blanch C, Gleeson JF, McGorry PD: Non-pharmacological management of antipsychoticinduced weight gain: Systematic review and meta-analysis of randomised controlled trials. Br J Psychiatry 193:101-107, 2008.

American Psychiatric Association: Diagnostic and Statistical Manual of Mental Disorders, 4th ed., Text Revision. Washington, DC: American Psychiatric Association; 2000.

Barnes TR: A rating scale for drug-induced akathisia. Br J Psychiatry 154:672-676, 1989.

Bauer M, Pfennig A: Epidemiology of bipolar disorders. Epilepsia 46(Suppl 4):8-13, 2005.

Bleich SN, Segal J, Wu Y, Wilson R, Wang Y: Systematic review of community-based childhood obesity prevention studies. Pediatrics 132:e201-e210, 2013.

Citrome L, Blonde L, Damatarca C: Metabolic issues in patients with severe mental illness. South Med J 98:714-720, 2005.

Cordes J, Thunker J, Regenbrecht G, Zielasek J, Correll CU, SchmidtKraepelin C, Lange-Asschenfeldt C, Agelink MW, Kahl KG, Gaebel W, Klimke A, Hauner H: Can an early weight management program (WMP) prevent olanzapine (OLZ)-induced disturbances in body weight, blood glucose and lipid metabolism? Twenty-fourand 48-week results from a 6-month randomized trial. World J Biol Psychiatry 15:229-241, 2014.

Correll CU, Carlson HE: Endocrine and metabolic adverse effects of psychotropic medications in children and adolescents. J Am Acad Child Adolesc Psychiatry 45:771-791, 2006.

Correll CU, Kane JM, Manu P: Obesity and coronary risk in patients treated with second-generation antipsychotics. Eur Arch Psychiatry Clin Neurosci 261:417-423, 2011.

Datta SS, Kumar A, Wright SD, Furtado VA, Russell PS: Evidence base for using atypical antipsychotics for psychosis in adolescents. Schizophr Bull 40:252-254, 2014.

Daumit GL, Dickerson FB, Wang NY, Dalcin A, Jerome GJ, Anderson CA, Young DR, Frick KD, Yu A, Gennusa JV, III, Oefinger M, Crum RM, Charleston J, Casagrande SS, Guallar E, Goldberg RW, Campbell LM, Appel LJ: A behavioral weight-loss intervention in persons with serious mental illness. N Engl J Med 368:1594-1602, 2013.

Eli Lilly and Company: Zyprexa (Olanzapine) [Package Insert]. Indianapolis (Indiana), 2013.

Faulkner G, Cohn T, Remington G: Interventions to reduce weight gain in schizophrenia. Cochrane Database Syst Rev CD005148, 2007.

Fromell GJ: Good clinical practice standards: What they are and some tools to support them. Hum Gene Ther 19:431-440, 2008.

Goldstein TR, Goldstein BI, Mantz MB, Bailey B, Douaihy A: A brief motivational intervention for preventing medication-associated weight gain among youth with bipolar disorder: Treatment devel- opment and case report. J Child Adolesc Psychopharmacol 21:275280, 2011.

Guy W: ECDEU Assessment Manual for Psychopharmacology, Revised 1976. Rockville, MD: National Institute of Mental Health, Early Clinical Drug Evaluation, Psychopharmacology Research Branch, 1976, pp. 217-222.

Hollis C: Adult outcomes of child- and adolescent-onset schizophrenia: Diagnostic stability and predictive validity. Am J Psychiatry 157:1652-1659, 2000.

Holt RI, Pendlebury J, Wildgust HJ, Bushe CJ: Intentional weight loss in overweight and obese patients with severe mental illness: 8-year experience of a behavioral treatment program. J Clin Psychiatry 71:800-805, 2010.

Jewell L, Abtan R, Scavone A, Timmins V, Swampillai B, Goldstein BI: Preliminary evidence of disparities in physical activity among adolescents with bipolar disorder. Ment Health Phys Act 8:62-67, 2015.

Kaufman J, Birmaher B, Brent D, Rao U, Flynn C, Moreci P, Williamson D, Ryan N: Schedule for Affective Disorders and Schizophrenia for School-Age Children-Present and Lifetime Version (K-SADS-PL): Initial reliability and validity data. J Am Acad Child Adolesc Psychiatry 36:980-988, 1997.

Kryzhanovskaya L, Schulz SC, McDougle C, Frazier J, Dittmann R, Robertson-Plouch C, Bauer T, Xu W, Wang W, Carlson J, Tohen M: Olanzapine versus placebo in adolescents with schizophrenia: A 6-week, randomized, double-blind, placebo-controlled trial. J Am Acad Child Adolesc Psychiatry 48:60-70, 2009a.

Kryzhanovskaya LA, Robertson-Plouch $\mathrm{CK}, \mathrm{Xu}$ W, Carlson JL, Merida KM, Dittmann RW: The safety of olanzapine in adolescents with schizophrenia or bipolar I disorder: A pooled analysis of 4 clinical trials. J Clin Psychiatry 70:247-258, 2009b.

Kryzhanovskaya LA, Xu W, Millen BA, Acharya N, Jen KY, Osuntokun O: Comparison of long-term (at least 24 weeks) weight gain and metabolic changes between adolescents and adults treated with olanzapine. J Child Adolesc Psychopharmacol 22:157-165, 2012.

Kumra S, Shaw M, Merka P, Nakayama E, Augustin R: Childhood-onset schizophrenia: Research update. Can J Psychiatry 46:923-930, 2001.

Lachar D, Randle SL, Harper RA, Scott-Gurnell KC, Lewis KR, Santos CW, Saunders AE, Pearson DA, Loveland KA, Morgan ST: The brief psychiatric rating scale for children (BPRS-C): Validity and reliability of an anchored version. J Am Acad Child Adolesc Psychiatry 40:333-340, 2001.

Loranger AW: Sex difference in age at onset of schizophrenia. Arch Gen Psychiatry 41:157-161, 1984.

Martin K, Woo J, Timmins V, Collins J, Islam A, Newton D, Goldstein BI: Binge eating and emotional eating behaviors among adolescents and young adults with bipolar disorder. J Affect Disord 195:88-95, 2016.

McClellan JM, Werry JS, Ham M: A follow-up study of early onset psychosis: Comparison between outcome diagnoses of schizophrenia, mood disorders, and personality disorders. J Autism Dev Disord 23:243-262, 1993.

McCormack PL: Olanzapine: In adolescents with schizophrenia or bipolar I disorder. CNS Drugs 24:443-452, 2010.

Moreno C, Merchán-Naranjo J, Alvarez M, Baeza I, Alda JA, Martinez-Cantarero C, Parellada M, Sánchez B, de la Serna E, Giraldez M, Arango C: Metabolic effects of second-generation antipsychotics in bipolar youth: Comparison with other psychotic and nonpsychotic diagnoses. Bipolar Disord 12:172-184, 2010.

Noguera A, Ballesta P, Baeza I, Arango C, de la Serna E, GonzalezPinto A, Parellada M, Graell M, Moreno C, Otero S, Castro-Fornieles $\mathrm{J}$ : Twenty-four months of antipsychotic treatment in children and adolescents with first psychotic episode: Discontinuation and tolerability. J Clin Psychopharmacol 33:463-471, 2013. 
Overall JE, Pfefferbaum B: The brief psychiatric rating scale for children. Psychopharmacol Bull 18:10-16, 1982.

Parsa-Parsi RW, Ellis R, Wiesing U: Fifty years at the forefront of ethical guidance: The world medical association declaration of Helsinki. South Med J 107:405-406, 2014.

Pavlickova H, Varese F, Smith A, Myin-Germeys I, Turnbull OH, Emsley R, Bentall RP: The dynamics of mood and coping in bipolar disorder: Longitudinal investigations of the inter-relationship between affect, self-esteem and response styles. PLoS One 8: e62514, 2013.

Pendlebury J, Bushe CJ, Wildgust HJ, Holt RI: Long-term maintenance of weight loss in patients with severe mental illness through a behavioural treatment programme in the UK. Acta Psychiatr Scand 115: 286-294, 2007.

Posner K: State of the Science: Measurement of Suicidal Adverse Events and the Columbia Suicide Severity Rating Scale. Boca Raton, NCDEU, 2007.

Posner K, Brown GK, Stanley B, Brent DA, Yershova KV, Oquendo MA, Currier GW, Melvin GA, Greenhill L, Shen S, Mann JJ: The Columbia-Suicide Severity Rating Scale: Initial validity and internal consistency findings from three multisite studies with adolescents and adults. Am J Psychiatry 168:1266-1277, 2011.

Post RM, Leverich GS, Kupka RW, Keck PE, Jr., McElroy SL, Altshuler LL, Frye MA, Luckenbaugh DA, Rowe M, Grunze H, Suppes T, Nolen WA: Early-onset bipolar disorder and treatment delay are risk factors for poor outcome in adulthood. J Clin Psychiatry 71:864-872, 2010.

Poulin MJ, Chaput JP, Simard V, Vincent P, Bernier J, Gauthier Y, Lanctôt G, Saindon J, Vincent A, Gagnon S, Tremblay A: Management of antipsychotic-induced weight gain: Prospective naturalistic study of the effectiveness of a supervised exercise programme. Aust $\mathrm{N}$ Z J Psychiatry 41:980-989, 2007.

Remschmidt H, Theisen F: Early-onset schizophrenia. Neuropsychobiology 66:63-69, 2012.

Savoye M, Shaw M, Dziura J, Tamborlane WV, Rose P, Guandalini C, Goldberg-Gell R, Burgert TS, Cali AM, Weiss R, Caprio S: Effects of a weight management program on body composition and metabolic parameters in overweight children: A randomized controlled trial. JAMA 297:2697-2704, 2007.

Showell NN, Fawole O, Segal J, Wilson RF, Cheskin LJ, Bleich SN, Wu Y, Lau B, Wang Y: A systematic review of home-based childhood obesity prevention studies. Pediatrics 132:e193-e200, 2013.
Simpson GM, Angus JW: A rating scale for extrapyramidal side effects. Acta Psychiatr Scand 212:11-19, 1970.

Strober M, Schmidt-Lackner S, Freeman R, Bower S, Lampert C, DeAntonio M: Recovery and relapse in adolescents with bipolar affective illness: A five-year naturalistic, prospective follow-up. Am Acad Child Adolesc Psychiatry 34:724-731, 1995.

Tohen M: Mania. In: Acute Care Psychiatry Diagnosis and Treatment. Edited by Sederer LI, Rotchschiled AJ. Baltimore, MD: Williams \& Wilkins, 1997, pp. 141-165.

Tohen M, Kryzhanovskaya L, Carlson G, Delbello M, Wozniak J, Kowatch R, Wagner K, Findling R, Lin D, Robertson-Plouch C, Xu W, Dittmann RW, Biederman J: Olanzapine versus placebo in the treatment of adolescents with bipolar mania. Am J Psychiatry 164:15471556, 2007.

Tschoner A, Engl J, Laimer M, Kaser S, Rettenbacher M, Fleischhacker WW, Patsch JR, Ebenbichler CF: Metabolic side effects of antipsychotic medication. Int J Clin Pract 61:1356-1370, 2007.

Usher K, Park T, Foster K, Buettner P: A randomized controlled trial undertaken to test a nurse-led weight management and exercise intervention designed for people with serious mental illness who take second generation antipsychotics. J Adv Nurs 69:1539-1548, 2013.

Weiden PJ, Mackell JA, McDonnell DD: Obesity as a risk factor for antipsychotic noncompliance. Schizophr Res 66:51-57, 2004.

World Health Organization. Growth Reference Data for 5-19 years, 2007. Available at www.who.int/growthref/who2007_bmi_for_age/ en (Last accessed October 15, 2015).

Wozniak J, Biederman J, Kiely K, Ablon JS, Faraone SV, Mundy E, Mennin D: Mania-like symptoms suggestive of childhood-onset bipolar disorder in clinically referred children. J Am Acad Child Adolesc Psychiatry 34:867-876, 1995.

Young RC, Biggs JT, Ziegler VE, Meyer DA: A rating scale for mania: Reliability, validity and sensitivity. Br J Psychiatry 133:429-435, 1978.
Address correspondence to: Holland C. Detke, PhD Lilly Corporate Center Eli Lilly and Company Indianapolis, IN 46285

E-mail:detkehc@lilly.com 
This article has been cited by:

1. Pierre S. Chue, Arno G. Siraki. Antipsychotic Drugs . [Crossref] 